\title{
IIIness As Narrative Strategy: An Account of IIIness Narratives and Popular Fiction
}

\author{
Kavya Shree P \\ Department of English, University of Madras, India
}

\begin{abstract}
Illness Narrative is a genre where a patient or people related to the patient narrate their story of illness. This paper explores the theme of illness in Popular Fiction, whose sole purpose is entertainment. Illness narrative in popular fiction focuses not just on illness as a theme but also on the tale that is narrated. The novels taken as representatives of the study are chosen for their popularity and impact on the readers. These novels, when closely read, reveal how narrative strategy is used in the process of healing. The paper also establishes how writing functions as a therapy for readers through analyzing and juxtaposing the novels A Walk to Remember, The Fault in our Stars, and, P.S. I Love You. It highlights the uniqueness of their approach in their portrayal of illness and the process of healing.
\end{abstract}

\section{KEY WORDS: ILLNESS NARRATIVES, POPULAR FICTION, NARRATIVE STRATEGY, THERAPY, HEALING.}

\section{INTRODUCTION}

The world is a balance of good and evil, right and wrong, light and dark. In this context, living beings are either sick or healthy. Like being healthy, sickness or illness is part and parcel of life. Though people are expected to live a happy life, no man on earth has ever lived a healthy, disease-free life. Thus, illness is an essential part of a man's journey of life. Chronic illness, in particular, does not just affect the body but also disrupts a person's mental health. It makes the victim rethink and re-examine his life and self - perception (Mazurek, 2015). American Physician Mike Berry reasons it out as a consequence of 'biographical disruption' (Bury, 2001; Mazurek, 2015). Biography is a person's story, including various experiences of their life. Disruption is a disturbance or problem which hinders an event or an activity. Together, biographical disruption describes the onset of illness that disrupts the victim's life (Mazurek, 2015).

Narrating their story that includes the sufferings and the patient's experience came out as a partial relief on the victim's part. Thus arose the illness narratives,

Biosc Biotech Res Comm P-ISSN: 0974-6455 E-ISSN: 2321-4007

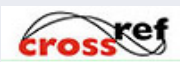

Identifiers and Pagination

Year: 2021 Vol: 14 No (8) Special Issue

Pages: 178-183

This is an open access article under Creative

Commons License Attribn 4.0 Intl (CC-BY).

DOI: $h t t p: / / d x . d o i . o r g / 10.21786 / b b r c / 14.8 .41$ which eventually gave way to the narration of stories by relatives and friends who travelled along with the victim (Mazurek, 2015). Illness narratives were defined as the "autobiographical accounts of illness spoken or written by patients" (Jurecic, 2012; Mazurek, 2015). It helped them rebuild the lost biographical continuity and cope with the harsh reality of life. They are either oral narratives that appear as a part of everyday conversations or written biographies and autobiographies that account for the patient and his illness. These narrations help in a better understanding of the illness and its ramifications (Mazurek, 2015).

According to American Psychiatrist Arthur Michael Kleinman, The illness narrative is a story the patient tells, and significant others retell, to give coherence to the distinctive events and long-term course of suffering. The plot lines, core metaphors, and rhetorical devices that structure the illness narrative are drawn from cultural and personal models for arranging experiences in meaningful ways and for effectively communicating those meanings. (...) The personal narrative does not merely reflect illness experience, but rather it contributes to the experience of symptoms and suffering. (Kleinman, 1988; Mazurek, 2015) This approach entails the illness narrative as it is created by the patient's conversation with the doctor, which helps determine its symptoms and treatment (Mazurek, 2015). The term illness narrative has gained a broader perspective in the present context. Any account, be it prose, poetry, or drama, which has the slightest mention of illness is considered an illness
Article Information

Received: $18^{\text {th }}$ May 2021

Accepted after revision: $24^{\text {th }}$ July 2021 
narrative (49). According to Medical Sociologist Arthur Frank, patients' narration during modern times mainly was using medical jargon. They were more clinical. "The physician becomes the spokesperson for the disease, and the ill person's disease come to depend heavily on the repetition of what the physician has said" (Frank, 2007; Mazurek, 2015).

Gradually, the patients became more involved with themselves and their illnesses during the postmodern era. Instead of talking about their condition just in medical terms, they narrated their experience with emotion and involvement. "The postmodern experience of illness begins when ill people recognize that more is involved in their experiences than the medical story can tell" (Frank, 2007; Mazurek, 2015). Henceforth, the stories were not said only to the doctors but became more of a conversation in waiting halls to fellow patients, family members, friends, relatives, and acquaintances. Each narration differed according to the listener (Mazurek, 2015).

Professor Ann Jurecic, author of Illness and Narrative, noted that specialists such as doctors, nurses, psychologists, and psychiatrists were the pioneers for creating illness narratives. They were the ones who initially published stories about illness in medical journals and press during the twentieth century. On the other hand, Jurecic discusses how Professor Sheila Rothman talks about the Sanatorium narratives. In the 1920s and '30s, Tuberculosis patients who were isolated from society wrote and published the so-called Sanatorium narratives (qtd. by Jurecic, 2012; Mazurek, 2015). They accounted for the patient's illness and their experience with other patients in the medical institution (Mazurek, 2015).

In the later years, there was significant growth in such accounts in terms of number and magnitude. By 1990, the genre became highly popular. A lot of narratives, including William Styron's Darkness Visible (1990), a memoir of depression, John Updike's Self-Consciousness (1989), about psoriasis, and Susanna Kaysen's Girl, Interrupted (1993), came into existence. Girl, Interrupted especially is of particular significance as it became the first memoir of this kind to be adapted into a movie in 1999. Other adaptations include John Bayley's Iris: A Memoir of Iris Murdoch (1998) which was adapted and released as a film in 2001, and Jean-Dominique Bauby's The Diving Bell and the Butterfly (1997), which was released in 2007 (Vickers, 2016). The time when a healthy community feared talking about illness in public spaces was slowly coming to an end.

Newspaper columns by people like John Diamond, Ruth Picardie, and Barbara Ehrenreich made the subject less of a taboo in the following years. To build on to that, online blogs like Kate Gross's ‘the nuisance: News from Kate’s attic on life, and cancer. In that order' made provision for honest and open communication about stories of illness (Vickers, 2016). Ann Jurecic notes that "The Internet has made possible the telling and preservation of personal stories in a way that wasn't possible more than 10 years ago. When you start exploring online, you realise that there's an ocean of these narratives out there" (Negrea, "Professor").

In literature, illness accounts are usually in the form of diaries, novels, and tales. They act as a guide to readers who try to comprehend the depth of the disease. Their practical experience of the illness and the firsthand narration grants a profound knowledge in the specified area (Mazurek, 2015). One disadvantage is that the dividing line between fact and fiction, authenticity, and creation is usually blurred in these kinds of narratives (Mazurek, 2015). "In this sense chronic illness narratives might be called 'Factions' rather than Fact or Fiction" (Bury, 1991; Mazurek, 2015). The first literary scholars working in the literature department to use the term illness narrative were G. Thomas Couser and John Wiltshire. Couser spoke for many when he argued that 'accounts of illness where life is literally at stake exposes a crucial divide between fiction and non-fiction' (Couser, 1997).

It was believed that literary scholars were reluctant to be involved in studies about the illness. The reason they initially indulged was to find out its connection to other cultures and streams (Vickers, 2016). Historicist critics such as George Sebastian Rousseau and Lilian Furst looked at the medicine of the past in order to show the multiple ways in which medical ideas ramified into other cultural domains. Here the goal was to demonstrate the hidden power of medicine in the culture of the past. Gay activists made a specialty of AIDS memoirs. Amongst feminists, Elaine Showalter and others contested the bona fides of medical concepts such as hysteria that have served to pathologise and oppress women; but with the signal exception of Susan Sontag's reflections on the mythologies of cancer in Illness as Metaphor (1978), remarkably little was written about the representation of breast cancer. Couser has said - rightly in my view - that the prolonged invisibility of illness in literary scholarship "reflects an all too common cultural denial of bodily dysfunction'. (Vickers, 2016) Still, the change did occur. This change was made possible by life-writing scholars and the inclusion of Disability Studies into the mainstream of literary studies (Vickers, 2016).

The increasing number of illness memoirs written by lays (...) is the consequence of a variety of changes in culture, medicine, media, and literacy over the past century, which include medical professionalisation; the rise of modern health care; the emergence of the women's movement (...); the inability of master narratives to give meaning to suffering in the modern era; and technological advances that promote self - publication and the global distribution of information. (Jurecic, 2012) It is predicted that such illness narratives will only grow more in the future as the ill are encouraged to share their story with the world. They are more aware of the illness than anyone else. These narratives' primary aim 
is to add meaning to the affected people's anxious and chaotic lives. They leave their mark in the world through these stories of their lives.

Illness Narratives In Popular Fiction: Illness as a theme is widely used in various media like books, movies and television series. It is a sought-after theme, especially in popular fiction. "Popular literature includes those writings intended for the masses and those that find favour with large audiences. It can be distinguished from artistic literature in that it is designed primarily to entertain" ("Britannica”, 2015). It includes any form of literature, such as poetry, play or novel, written with the sense of popularity. Illness narratives in popular fiction is a widespread phenomenon. The theme of illness complements the genre by determining the factors like popularity, entertainment, being a best seller, etc., which are the features of popular fiction (Maheboob "Popular"). There are different types of stories, but no definite classification. Popular romance novels taken for study under this genre are John Green's The Fault in Our Stars, Nicholas Sparks' A Walk to Remember, and Cecilia Ahern's P.S. I Love You. They are studied as representatives of illness narratives in popular fiction. Other well-known novels of this genre are Five Feet Apart by Rachael Lippincott, Zac and Mia by A.J. Betts, Everything, Everything by Nicola Yoon, Side Effects May Vary by Julie Murphy and so on. Several of these novels are also adapted into movies.

An important question to be asked in this field of study is what such narratives accomplish. In this context, five uses of the illness narratives as mentioned by LarsChrister Hyden in his article "Illness and narrative" are as follows: "1. to transform illness events and construct a world of illness; 2 . to reconstruct one's life history in the event of a chronic illness; 3 . to explain and understand the illness; 4 . as a form of strategic interaction in order to assert or project one's identity; and lastly, 5. to transform illness from an individual into a collective phenomenon" (Hyden, 1997). According to Hyden, "The advantage of studying illness narratives is that they make it possible to study the experience of illness from a number of vantage points: as a social and cultural construct, as a transformation and expression of bodily suffering, and most of all as the suffering person's attempt to construct his or her world, to find his or her own life-work and life context” (Hyden, 1997).

Stories have a way of easing the pain both to the listener and the one who narrates it. When told, it is a means of sharing the pain. It helps to unload a burden that the speaker carries within. On the other hand, listening to a story puts your mind to rest, knowing that there are people who go through tough times than ourselves. Also, it helps to connect with the narrator in an unsaid way that aids in escaping the loneliness of the real world. “... [I]llness is terrible but, with some luck, it can also be full of wonders," Arthur W Frank is convinced. "The terrors assault us at once; the wonders take longer to become visible. Stories help us gain some distance from the terrors and learn to perceive the wonders .... In telling all kinds of stories, we find healing” (Frank, 1995).

Popular fiction, in particular, is known for the effect it creates on its readers. The focus of popular fiction is the way the story is narrated. Illness narrative in Popular fiction does not just focus on the theme of illness but also on the tale that is being narrated. The story here is not some random tale but that which uses the theme of illness in healing. It helps to look at illness from a positive light. It gives a sense of assurance to the readers that this too shall pass. Illness is thus carefully handled as a narrative strategy that offers hope to the readers.

Illness In A Walk To Remember: One of the familiar genres of popular fiction is romance. The element of love, combined with a grave illness, often grabs the attention of the readers. One such novel is A Walk to Remember by Nicholas Sparks. Nicholas Charles Sparks is a well-known American Novelist. A Walk to Remember is Sparks' third novel published in October 1999. The narrative is set during the 1950s in the small town of Beaufort, North Carolina. The story follows the life of seventeen-yearold Landon Carter, who unexpectedly, yet profoundly falls in love with a pious, seemingly unattractive girl Amy Sullivan. Unfortunately, Amy is diagnosed with a rare type of cancer that changes Landon's life. Landon narrates it at the age of fifty-seven.

The novel was inspired by Sparks' sister Danielle Sparks Lewis who also suffered from a grave illness. It was written with the idea that Jamie would die eventually. But when Sparks had completed the novel, his sister was still alive, making him have an open ending. His sister did not read the novel as she did not want to know how it ended (Sparks, "Inspiration"). Illness plays a secondary role in this novel. The narrative based on disease is in the background, but its result changes the novel's course. On the surface, illness acts as a symbol of peace that mends broken relationships. Once Jaime's condition is revealed, Landon's father helps her financially so that she can die peacefully at home, as per her wish. This act brings the father and son together and resolves the age-old feud between Worth Carter and Reverend Sullivan. Landon's friends like Eric and Margaret, who were mean to Jaime, realise their mistake and genuinely apologise to her. Eric goes to the extent of collecting money for the orphanage, which shows his sincerity. Jaime was considered a weird girl, but the revelation of her sickness brought together a church full of people on her marriage. Above all, Jaime's illness helped Landon grow as a person.

Illness not just affects the characters but also brings in a change in the readers. The narrative is in such a way that it brings out the emotions of the reader. It is what every interesting book does. But what makes A Walk to Remember unique from other texts is that it is also cerebral. It makes the reader feel for the characters and think as to how a drastic change is brought into each character, especially the protagonist of the novel. Reading the novel affects normal healthy people, but on the other hand, the ill identify themselves with the female lead of the story. They live the life of Jaime as 
they pass through the pages and feel the joy and pain she undergoes in her life. People who read the book for entertainment, who had chosen the book as a part of romance fiction, are in for a surprise when Jaime's illness is revealed. Though they read it only for entertainment, they come to the end just to know what happens to the couple. But when a sick person reaches the novel's zenith, they hope for a miracle just like Landon. When Landon desperately searches for the missing puzzle, readers are curious and anxious for the same.

The ill, in particular, hope for a miracle in the life of Jaime to give them a sense of comfort. The miracle Landon mentions at the end of the novel might be anything. But for a desperate reader, it provides hope and fulfilment. The miracle might be that Jaime was cured or that the turn his life had taken after their marriage. If it was the former, though it may not sound believable, it gives them positive energy. If it were the latter, they might feel comfortable that their loved ones would have a peaceful life even if something terrible were to happen to them. The fact that it made more impact on the ill is confirmed by Sparks' sister Danielle, who refused to read the novel as she was afraid of the ending. She did not want to know what might happen next in her life, as she would relate to Jaime. That is the kind of impact this novel would make on any reader, especially on sick people. Thus, A Walk to Remember is a narrative that helps the reader in the process of healing.

IIIness In The Fault In Our Stars: The Fault in our Stars by John Green is another novel which deals with illness as the central element. Hazel Grace Lancaster is a sixteenyear-old teenager who has thyroid cancer. She is forced by her mother to attend a support group where she meets the handsome and charming seventeen-year-old Augustus Waters, who is currently in remission. They bond over a few exchanges, which eventually turn into a deep affection for each other. Alas! Time is their enemy. Augustus's cancer returns and ultimately takes his life away, leaving Hazel with a different perspective on life. Illness, being the heart of the story, performs the role of a mediator. It brings the characters together and transcends them to attain spiritual maturity. The novel shows it is crucial for people around the sick to care for and support them physically and emotionally. However, they should not force the ill to participate in the happenings around them. This might result in feeling pressured on the part of the ill. The sick people need their own space and an environment to vent out their emotions. Bottling up of emotions might lead to sudden bursting out at an inappropriate time.

One important takeaway from this novel is that the ill wants to be treated just like any other normal person. Their lives are as rich and exciting as healthy people. Instead of pitying and shadowing over them every minute of their life, it is better to respect their personal space and, if possible, to treat them as normal human beings. In conclusion, illness here is something of an encouragement, one that could take you down into the darkness, and it would still give you light (Zemler, 2014).
As Tara Jafari Berenji writes in her review, "Their 'little infinity' reminds you that even the most heart-wrenching love story can be poetic, intelligent, humorous and full of positivity, even when you know there's no chance of ever having a 'fairy-tale' ending” (Berenji, "Fault").

IIIness In P. S. I Love You: Loss and coping mechanisms are essential factors to be discussed when talking about illness. Not all illnesses can be cured. Despite the scientific advancement at the present age, there are still several cases where no medicine or technology is helpful. As a result, death and loss are inevitable in the life of human beings. Human beings are known to overcome any grief as time passes. But for some, it is more challenging than it is for others. They feel that losing a loved one has made it impossible for them to move on further in their lives. Following is the narrative of one such widow who moans the loss of her beloved husband. P. S. I Love You by Cecelia Ahern analyses the healing process undergone by the protagonist Holly Kennedy.

Holly had just lost her beloved husband and best friend with whom she had dreamt of spending the rest of her life. Gerry had been the guiding light in the darkness and had accompanied her through thick and thin. Without him, Holly seems to have lost a part of herself. Gerry was aware that Holly would find it difficult to move on without his support, as she had always depended on him. Hence, he leaves behind a series of instructions in the form of letters that would help her move forward in life. This technique of leaving behind a message for the loved ones is the novel's sequel Postscript's central tool. Several sick people inspired by Gerry's idea for Holly come together and form the so-called P.S. I Love You club. They approach Holly to assist them with ideas for their loved ones to cope with grief and loss after their death. As the story progresses, she reluctantly goes along with their plan after serious contemplation.

Holly tries hard to hide her sadness in front of her friends and family. Yet when she visits places and people she used to meet with Gerry, the reality of her loneliness hits hard. Like every other person who has lost a loved one, who feels that the world moves on, but he/she is stuck in a place unable to move forward, Holly thinks the same. Though she loves her friends very much, the news of Sharon's pregnancy and Denise's engagement leaves Holly lonely and back into her shell. It is hard for her to accept that her two best friends are moving forward with their lives while she is still a grieving widow who has no hope whatsoever. Leading the life of a young widow is not very easy. Holly had to overcome several obstacles, like escaping the eyes of onlookers who judge her for moving on with her life. In addition to coping with the loss of her beloved, she must deal with the scorn of society. In times like these, she misses Gerry, her guardian angel.

Through this arduous journey, Holly learns a lot of life lessons. She understands the value of family and friends. She recognises people's true selves; not all are how they portray to be, and that constitutes life. With 
Gerry's words of wisdom, Holly sets out on a new path of searching for her true potential. She discovers that she is capable of leading an independent and responsible life. She realises that even if Gerry is no longer with her, she can live gracefully with his beautiful memories. "Life is for living, she realises - but it always helps if there's an angel watching over you" ("Overview”).

\section{CONCLUSION}

Though illness narrative is a developing genre, it is considered a mode of reading while analysing these novels. Illness plays different roles in the three stories. In A Walk to Remember, illness is used in the background as a peace offering factor that helps to mend relationships. Also, in the end, it rejuvenates a sense of hope in the readers. The Fault in our Stars uses illness as a central feature that brings the protagonists together. It renders the message that death is not the ultimate end; even after a person dies, their relationship lasts in their loved ones' memories. This idea is reiterated in depth in P.S. I Love You. Life must go on even after the demise of our loved ones. Though it might seem impossible at that time, with some help from our friends and family, it is viable to start a new chapter in life.

Taking the gender of writers into consideration, it can be said that Sparks and Green lay out the message to a general audience. At the same time, Ahern portrays the difficulties of being a woman, a widow who has to confront the harsh society after her husband's death. In A Walk to Remember, considering Jaime to be dead, Landon does not seem to have faced any difficulties from society's side. In The Fault in our Stars Hazel and Augustus are not married. Hence, society does not bother to question them. On the other hand, a woman writer aptly portrays a widow's suffering against the malicious community.

At present, entertainment media, such as films, television shows and music videos, commercialize illness for their personal benefits. They exaggerate the effect of illness as a means of gaining sympathy from the audience. On the other hand, illness is also being portrayed comically as a means of erupting laughter. These are the dangerous extremes that illness as a factor face in the field of entertainment media. To conclude, as Frederick Lenz quotes, "even sickness becomes an experience that we pass through in happiness because our happiness is not dependent upon how our body feels, but how our spirit feels" ("Frederick"). With the increasing number of diseases in the present age, it is crucial to stay positive even when it seems impossible. "Illness or pain is just an extension of negative emotion. When you are no longer feeling any resistance to it, it becomes a nonissue" (Hicks, 2017).

\section{REFERENCES}

Ahern, Cecelia. P.S. I Love You. Harper Collins Publishers, 2007.

"Book Reviews - PS, I Love You by Cecelia Ahern." Www.Clarelibrary.Ie, www.clarelibrary.ie/eolas/library/ services/book_reviews/ps_iloveyou.htm. Accessed 10 March 2021.

Berenji, Tara Jafari. "The Fault in Our Stars. Book Review by Tara Jafari Berenji.” Www.Orleanspark.Richmond. Sch.Uk, www.orleanspark.richmond.sch.uk/the-fault-inour-stars-book-review-by-tara-jafari-berenji/287103. html. Accessed 8 March 2021.

Biography. Nicholas Sparks. 2019, https://www. biography.com/writer/nicholas-sparks. Accessed 8 March 2021.

Britannica, The Editors of Encyclopaedia. "Popular art". Encyclopedia Britannica, 23 Sep. 2015, https://www. britannica.com/art/popular-art. Accessed 20 March 2021.

Bury, Michael.( 1991) "The Sociology of Chronic Illness: A Review of Research and Prospects.” Wiley Online Library, Dec., doi.org/10.1111/j.1467-9566.1991. tb00522.x. Accessed 20 March 2021.

Bury, Mike.( 2001) "Illness Narratives: Fact or Fiction?" onlinelibrary.wiley.com. vol.23, no.3, pp. 263-265, https://onlinelibrary.wiley.com/doi/pdf/10.1111/14679566.00252. Accessed 8 March 2021.

Couser, G. Thomas.( 1997) Recovering Bodies: Illness, Disability and Life Writing. University of Wisconsin Press.

Dasgupta S, Charon R. (2004) "Personal illness narratives: using reflective writing to teach empathy." Acad Med. vol. 79, no. 4, Apr, pp.351-56.

Djinis, E. (2017) )"Nicholas Sparks' Books Are Based on True Stories, Author Says at Bradenton Talk.” Sarasota Herald-Tribune, https://www.heraldtribune.com/ news/20170207/nicholas-sparks-books-are-based-ontrue-stories-author-says-at-bradenton-talk. Accessed 8 March 2021.

Frederick Lenz Quotes. (2021) "Quotefancy.com, quotefancy.com/frederick-lenz-quotes. Accessed 20 March.

Frank, Arthur W. (2007 ) "Stories and healing; observations on the progress of my thoughts." Anchorage (AS), Mar 20, http://litsite.alaska.edu/ healing/frank.html.

Frank, Arthur W. (1995) The Wounded Storyteller: Body, Illness and Ethics. University of Chicago Press.

Green, John. (2014) The Fault in Our Stars. Penguin Books.

Hicks, Abraham. (2017 ) "101 Abraham-Hicks Quotes about Health \& Physical Well-Being.” Christa Smith, 28 Aug., www.christa-smith.com/101-abraham-hicksquotes-about-health/. Accessed 20 March 2021.

Hyden, Lars Christer.( 1997) "Illness and Narrative." Sociology of Health \& Illness, Sep, pp. 48 - 69, 10.1111/ j.1467-9566.1997.tb00015.x.

Hydén, Lars Christer. (2007 ) "Illness Narrative.” In the Blackwell Encyclopedia of Sociology, G. Ritzer (Ed.),. doi:10.1002/9781405165518.wbeosi016

Jurecic, Ann.( 2012) Illness as Narrative. University of Pittsburgh Press. 
Kleinman, Arthur Michael. (1988) The Illness Narrative: Suffering, Healing and the Human Condition. BasicBooks,.

Maheboob, Mangrule Toufik. "Popular Fiction: Some Theoretical Perspectives." Epitomejournals.com, http://www.epitomejournals.com/VolumeArticles/ FullTextPDF/368_Research_Paper.pdf. Accessed 11 March 2021.

Mazurek, Emilia. (2015) "Illness Narratives - Between Personal Experience, Medical Discourse and Cultural Practice." Hrvatska revija za rehabilitacijska istraživanja, vol. 51, no.1, pp.48-58. Accessed 8 March 2021. Murray, Bridget. (2002) "Writing to Heal.” https://Www. Apa.Org, June, www.apa.org/monitor/jun02/writing. Accessed 10 March 2021.

Negrea, Sherrie. "Professor Examines How Illness Fueled A Literary Genre.” Rutgers University, School of Arts and Sciences, https://sas.rutgers.edu/20-newsevents-main/publications/1298-professor-examineshow-illness-fueled-a-literary-genre. Accessed 8 March 2021.

"Overview.” Www.cecelia-Ahern.com, www.cecelia- ahern.com/books-inner-pages/ps-i-love-you. Accessed 20 March 2021.

O'Connor, Meg.( 2015) "Evidence of the Healing Power of Expressive Writing.” The UnLonely Project, 13 July, www.artandhealing.org/evidence-of-the-healingpower-of-expressive-writing/. Accessed 10 March 2021.

Postscript. HarperCollins Publisher, 2019.

Sparks, Nicholas. (2021) "Inspiration for The Notebook." Nicholassparks.com. Accessed 10 March.

Sparks, Nicholas. (2006) A Walk to Remember. Time Warner Books.

Vickers, Neil. “Illness Narrative as Life Writing.” King's College London, https://www.kcl.ac.uk/study/coursesdata/modules/7/Illness-Narrative-As-Life-Writing7AAEM631. Accessed 9 March 2021.

Vickers, Neil. (2016) "Illness narratives.” A History of English Autobiography, Cambridge University Press, , pp. 388-401.

Zemler, Emily. (2014) “John Green: 'The Fault in Our Stars’ Doesn't Belong to Me.” ELLE, 4 June, www. elle.com/culture/movies-tv/news/a19308/john-greeninterview/. Accessed 8 March 2021. 